\title{
Evaluation of CD64 Index in HBV and in Chronic HCV Infections
}

\section{Hasan Sedeek Mahmoud1, Sanaa Shaker Aly², Heba Ahmed Osman', Asmaa Mohamed Zahran³, Muhammad Abbas El Masry4}

${ }^{1}$ Tropical Medicine and Gastroenterology Department, Qena Faculty of Medicine, South Valley University, Qena, Egypt

${ }^{2}$ Clinical and Chemical Pathology Department, Qena Faculty of Medicine, South Valley University, Qena, Egypt

${ }^{3}$ Oncological Clinical Pathology Department, South Egypt Cancer Institute, Assiut University, Assiut, Egypt

${ }^{4}$ Internal Medicine Department, Division of Gastroenterology, Assiut Faculty of Medicine, Assiut, Egypt

Email:hasan_sedeek@yahoo.com

How to cite this paper: Mahmoud, H.S., Aly, S.S., Osman, H.A., Zahran, A.M. and El Masry, M.A. (2017) Evaluation of CD64 Index in HBV and in Chronic HCV Infections. Open Journal of Gastroenterology, 7, 173-186.

https://doi.org/10.4236/ojgas.2017.76019

Received: April 25, 2017

Accepted: June 27, 2017

Published: June 30, 2017

Copyright $\odot 2017$ by authors and Scientific Research Publishing Inc. This work is licensed under the Creative Commons Attribution International License (CC BY 4.0).

http://creativecommons.org/licenses/by/4.0/

\begin{abstract}
Background and aims: CD64 [Fc gamma receptor $1(\mathrm{Fc} \gamma \mathrm{RI})]$ is a promising biomarker used in predicting severe bacterial infection. The study was designed to assess their level in all stages of HBV infection and in chronic HCV infection before and after treatment with direct acting antiviral therapy as a possible biomarker of inflammation. Patients and methods: A case-control study was conducted, 50 patients with different disease stages of HBV infection (10 acute, 15 chronic hepatitis, 15 liver cirrhosis (LC) and 10 with hepatocellular carcinoma (HCC)), twenty patients with chronic HCV and 15 as a control group. Laboratory and imaging studies were evaluated. The levels of CD64 expressions in peripheral blood and CD64 Index were measured for all patients by flowcytometry using fluorescein isothiocyanate (FITC)-conjugated anti-CD64 monoclonal antibody. Results: The levels of CD64 expressions in peripheral blood and CD64 index were significantly higher in patients with HBV and HCV than in control group ( $\mathrm{P}$ value $=0.01,0.01$ and $0.000,0.000$ respectively). They were increased significantly with disease progression in patients with HBV infection, acute hepatitis B infection showed the highest values. Their levels were significantly decreased in patients with HCV infection post treatment than before treatment. Conclusions: The levels of CD64 expressions in peripheral blood and CD64 index are considered good biomarkers of inflammation in viral hepatitis both $\mathrm{B}$ and $\mathrm{C}$ and could detect disease progression and also suppression of inflammation after antiviral therapy.
\end{abstract}

\section{Keywords}

CD64, HBV, HCV 


\section{Introduction}

Hepatitis $\mathrm{C}$ virus (HCV) infection is one of the main causes of chronic liver disease worldwide; 170 million people are chronically infected with HCV [1], and its long term impact is highly variable, ranging from minimal histological changes up to cirrhosis with or without the development of HCC [2].

The main goal of treatment of HCV is to cure the infection by viral eradication. The sustained virological response (SVR) is associated with resolution of liver disease in patients without cirrhosis and reduces; but not eliminates, the risk of life-threatening complications such as hepatic failure and portal hypertension in patients with cirrhosis [3] [4].

Worldwide, about one third of population has serological evidence of past or recent infection with HBV. It is estimated that 240 million people are chronically infected with HBV [5] with a highest prevalence in Africa and Asia [6].

The natural history of chronic HBV infection can be divided into five phases depending on HBV replication, $\mathrm{HBeAg}$, aminotransferase and the degree of hepatic necro-inflammation [7] [8].

Failure of detection and persistence of $\mathrm{HBV}$ or $\mathrm{HCV}$ infections increases the incidence of HCC; it constitutes the fifth most common cancer of all cancers [9].

The common markers used clinically to detect the degree of HBV inflammation are alanine aminotransferase (ALT) and HBV-DNA, but they cannot describe the actual state of the liver, some cases have HBV associated LC or hepatocellular carcinoma with normal levels of ALT and undetected HBV-DNA [10].

CD64 [ $\mathrm{Fc}$ gamma receptor $1(\mathrm{Fc} \gamma \mathrm{RI})]$ is a promising biomarker used in predicting severe bacterial infection and could be used as a simple and also as a predictive test for diagnosing and monitoring bacterial infections in hospitalized patients [11]. Wang et al., 2015 reported that, a neutrophil CD64 expression is a helpful marker in the early diagnosis of sepsis in critically ill patients [12].

Not only bacterial infection, but also, CD64 index could be used in diagnosis of viral infections, as Human Cytomegalovirus (CMV) [13], Epstein-Barr virus (EBV) [14] or other DNA virus [15].

A recent study focused on evaluating the relation between CD64 index in peripheral blood in different stages of chronic HBV and the degree of liver cell damage [10].

\section{Aim of the Study}

The current study aimed to assess CD64 expressions and CD64 index levels in all disease stages of HBV infection and in chronic HCV infection before and after treatment with direct acting antiviral therapy as a possible biomarker of inflammation.

\section{Patients and Methods}

\subsection{Patients}

This prospective (case-control) study was carried out on 70 patients; whom at- 
tending outpatient clinic of Tropical Medicine \& Gastroenterology department, Qena University Hospital; 50 with HBV, 20 with HCV infection and 15 subjects as a control group, from January 2016 to January 2017.

Patients with HBV infection were categorized according to their presentation into; 10 patients with acute hepatitis, 15 with chronic hepatitis, 15 with LC and 10 patients with HCC related HBV infection. Twenty patients with chronic HCV infection were included and were treated according to the Egyptian protocol of the national committee for control of viral hepatitis. Their diagnosis was based on combination of history, examination, laboratory and imaging investigations including fibroscan.

According to the Egyptian protocol for treatment of chronic HCV infection; which is based on the EASL guidelines for treatment of HCV [16]; patients were divided into two groups: patients easy to treat (naïve patients with serum bilirubin $\leq 1.2 \mathrm{mg} / \mathrm{dl}$, serum albumin $\geq 3.5 \mathrm{gm} / \mathrm{dl}$, INR $\leq 1.2$ and platelet count $\geq$ $150 \times 10^{3} / \mu \mathrm{l}$ and they received sofosbuvir $400 \mathrm{mg}$ and daklatasvir $60 \mathrm{mg}$ once daily for 3 months) and those difficult to treat (serum bilirubin $\geq 1.2 \mathrm{mg} / \mathrm{dl}$, serum albumin $\leq 3.5 \mathrm{gm} / \mathrm{dl}$, INR $\geq 1.2$ and platelet count $<150 \times 10^{3} / \mu \mathrm{l}$ and interferon experienced patients and they received sofosbuvir $400 \mathrm{mg}$ and daklatasvir $60 \mathrm{mg}$ and dose-weighted ribavirin ( $800-1200 \mathrm{mg}$ ) daily for 3 months. The duration of this regimen should be extended to 6 months if failed previous treatment with sofosbuvir and ribavirin).

The exclusion criteria for this protocol were: serum bilirubin $>3 \mathrm{mg} / \mathrm{dl}$, serum albumin $<2.8 \mathrm{gm} / \mathrm{dl}$, INR $\geq 1.7$ and platelet count $<50 \times 10^{3} / \mu \mathrm{l}$, pregnancy and presence of dynamic CT imaging of HCC or inadequately controlled diabetes mellitus; HbA1c > 9\%. Also patients were excluded from the study if they experienced any type of infection or bleeding varices.

All included patients underwent: history taking, clinical examination and laboratory investigations including: complete blood count, complete liver function test, HBs Ag, HCV Ab, PCR HBV DNA, PCR HCV RNA, serum glucose and serum creatinine. Serum alpha fetoprotein protein was measured for suspected patients with HCC. Abdominal US examination was done for all patients.

\subsection{Sampling}

Eight $\mathrm{ml}$ of venous blood were collected from patients and control groups under aseptic precautions. Two samples were collected from patients with HCV infection; one at base line; before treatment and the other at 3 months after treatment (SVR, 3 months). Samples were divided as follow: $2 \mathrm{ml}$ was placed in EDTA (Ethylene Diamine Tetra-acetic Acid) containing vacutainer tube to do complete blood count using automated hematology analyzer cell dyne-1800 (Abbott diagnostics, USA). $4 \mathrm{ml}$ was taken in plain glass tube and after clotting, the tube was centrifuged at $2000 \mathrm{rpm}$ for $3 \mathrm{~min}$ at the room temperature $\left(37^{\circ} \mathrm{C}\right)$ and the serum was separated for estimation of liver function using Cobas c311 automated chemistry analyzer (Roche diagnostics, Germany). The rest of the sample was placed in EDTA containing vacutainer tube for flowcytometric determina- 
tion of CD64 using FACS caliber flowcytometer (BD, Bectom Dickinson). All antibodies were obtained from Bectom Dickinson

CD64 expression and by flow cytometry: CD64 expression was measured using FITC CD64 monoclonal antibodies as follow: $100 \mu \mathrm{L}$ from blood samples and $10 \mu \mathrm{l}$ of FITC CD64 conjugated monoclonal antibody or matched isotype controls was added each in prepared tube then vortex and incubated in dark for $15 \mathrm{~min}$ at room temperature. Following incubation, red blood cells lysing solution $1 \mathrm{ml} ; 1 \times$ (BD Biosciences) was added and incubated for an additional 10 min at room temperature. Cells were centrifuged at $3500 \mathrm{rpm}$ for 5 minute. The pellet was washed twice with phosphate buffered saline and then they were suspended in BD Biosciences fluid sheath for analysis on a FACS Calibur flow cytometer, BD Biosciences. Acquisition and analysis were performed using cell Quest software. The acquisition and analysis of immuno-marked cells was Standardized for 10,000 events per sample. Lymphocytes, monocytes and neutrophil were gated in the R1, R2 and R3 region according to the characteristic linear forward and side scatter features. CD64 expression was evaluated on a logarithmic scale for three regions (Figure 1).

Neutrophil CD64 index was calculated as follow: CD64 index $=$ (neutrophil CD64 average fluorescence intensity/lymphocyte CD64 average fluorescence intensity)/(monocyte CD64 average fluorescence intensity/neutrophil CD64 average fluorescence intensity). We used CD64 expression on lymphocytes as internal negative control, while CD64 expression on monocytes was used as internal positive control.

\subsection{Ethical Approval}

The study protocol was approved by the ethical committee of our institution. All selected patients provided informed consent before enrollment in the study.

\subsection{Statistical Analysis}

The data first were coded and verified before its entry. Computer program Statistical Package for Social Sciences (SPSS) (ver.21) Chicago, USA was used for analyzing the collected data and for drawing figures. Data expressed as mean \pm standard deviation and number, percentage. Student- $t$-test and ANOVA tests were used to determine the significant difference for numeric variable. Chi. Square was used to determine the significant values for categorical variable. Person's correlation was used for correlations between groups. $\mathrm{P}$ value is considered significant when $\mathrm{P}$ value $<0.05$ and not significant when $\mathrm{P}$ value $>0.05$.

\section{Results}

\subsection{The Demographic Data of the Two Groups}

Patients with HBV were 39 males (78\%) and 11 females (22\%) with their mean ages were $45.16 \pm 15.38$. Patients with HCV were 15 males $(75 \%)$ and 5 females (25\%) with their mean ages were $42.5 \pm 12.84$ and 15 subjects matched for age and gender as a control group; this is summarized in Table 1. 


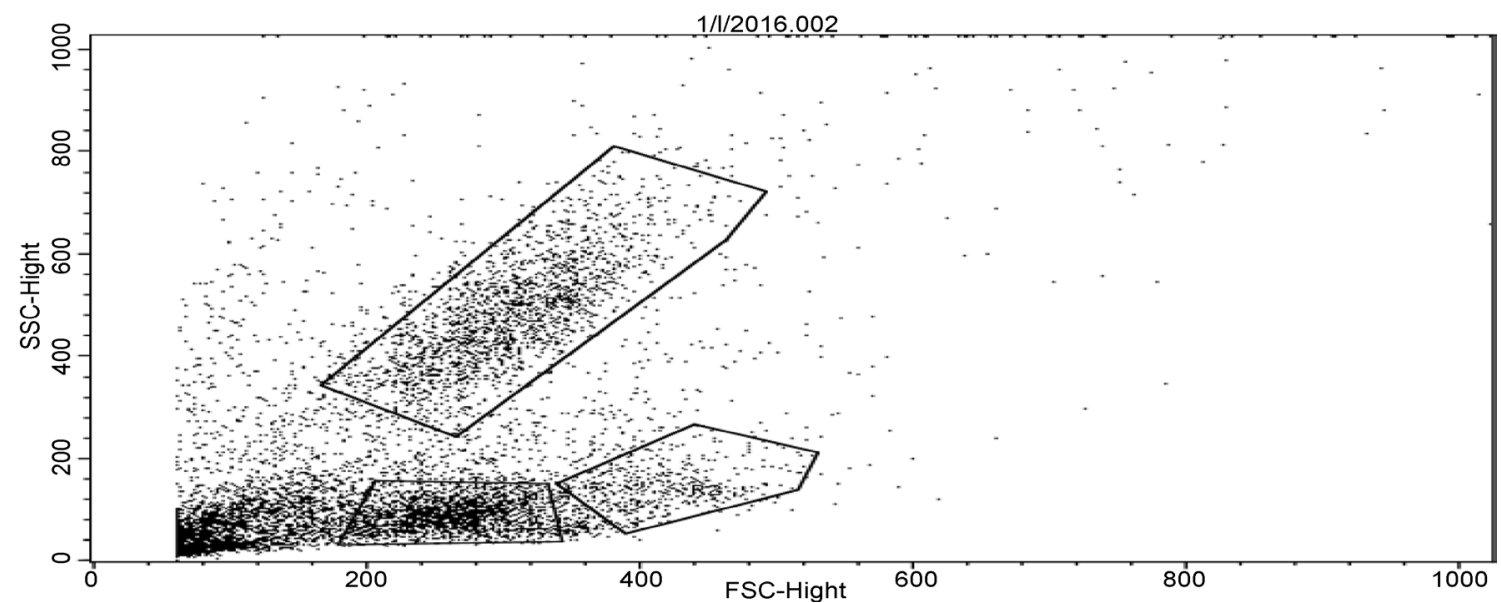

(a)

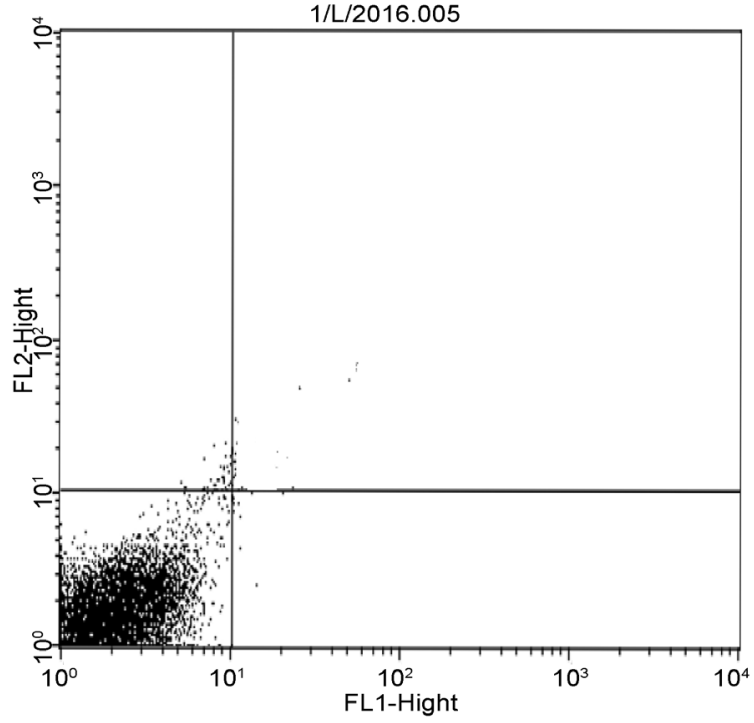

(b)

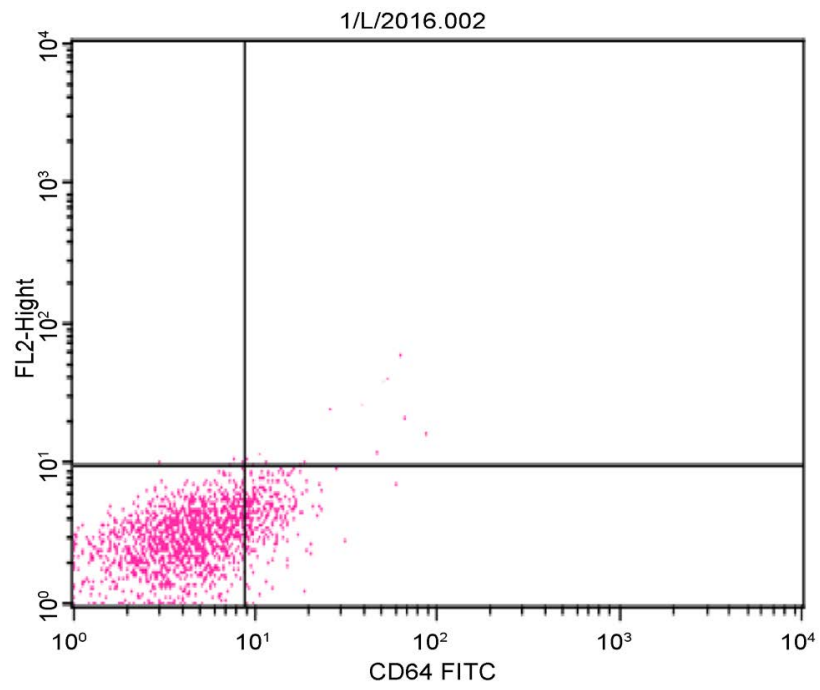

(d)

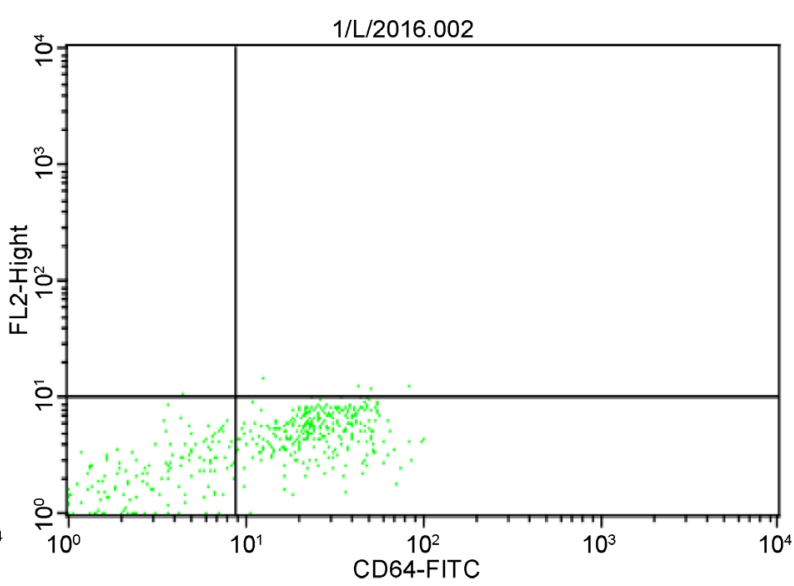

(c)

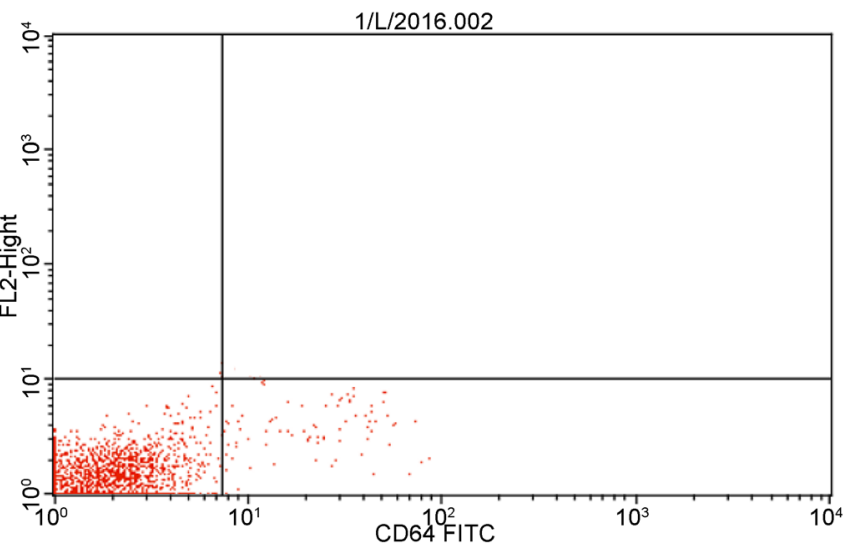

(e)

Figure 1. Peripheral blood expression of CD64: (a) Forward scatter, side scatter of peripheral blood; (b) Isotype control to exclude non-specific background staining; (c) Expression of CD64 onneutrophils; (d) Expression of CD64 onmonocytes; (e) Expression of CD64 onlymphocytes. 
Patients with HCV infection, treated with direct acting antiviral therapy, were as follow; $15(75 \%)$ patients were easy to treat and 5 (25\%) were difficult to treat; only one of them was sofosbuvir and ribavirin experienced and no interferon experienced patients. All patients with $\mathrm{HCV}$ infection showed negative PCR HCV RNA at the end of treatment with end treatment response $(\mathrm{ETR}=100 \%)$ and SVR; 3 months $=100 \%$.

\subsection{The Mean Values of Laboratory Data for Patients with HBV}

Laboratory data for patients with acute, chronic hepatitis, LC-HBV and HCCHBV are illustrated in Table 2.

\subsection{The Mean Values of Laboratory Data for Patients with HCV}

Laboratory data for patients with HCV before and after treatment (3 months) are illustrated in Table 3. Statistically significant reduction in bilirubin, ALT, AST, INR and increase in Hemoglobin level and Prothrombin concentration were detected after treatment with direct acting antiviral therapy for HCV infection.

Table 1. Characteristic demographic data for patients and control.

\begin{tabular}{cccc}
\hline \multirow{2}{*}{ Parameter } & \multicolumn{3}{c}{ Patients and control } \\
\cline { 2 - 4 } & control & HBV & HCV \\
\hline Number & 15 & 50 & 20 \\
Age & $49 \pm 10.5$ & $45.16 \pm 15.38$ & \\
Gender & $7(70)$ & $39(78)$ & $15(75)$ \\
Male & $3(30)$ & $11(22)$ & $5(25)$ \\
female & & &
\end{tabular}

Data expressed as mean \pm SD or number $(\%)$.

Table 2. Laboratory data for patients with HBV infection.

\begin{tabular}{ccccc}
\hline Parameter & \multicolumn{3}{c}{ HBV disease stage } \\
\cline { 2 - 5 } & acute & chronic & cirrhosis & HCC \\
\hline Bilirubin $(\mathrm{mg} / \mathrm{dl})$ & $4.90 \pm 3.21$ & $1.27 \pm 0.23$ & $1.76 \pm 0.63$ & $1.96 \pm 0.60$ \\
Albumin $(\mathrm{g} / \mathrm{dl})$ & $3.76 \pm 0.08$ & $4.0 \pm 0.28$ & $3.2 \pm 0.71$ & $3.12 \pm 0.56$ \\
ALT $(\mathrm{U} / \mathrm{L})$ & $607 \pm 353$ & $25.4 \pm 15.5$ & $66.9 \pm 20.4$ & $48 \pm 15.6$ \\
AST $(\mathrm{U} / \mathrm{L})$ & $675 \pm 501$ & $21.4 \pm 12.9$ & $53 \pm 16.1$ & $40 \pm 18.1$ \\
PT $(\mathrm{seconds})$ & $14.4 \pm 3.3$ & $11.6 \pm 0.5$ & $18.9 \pm 10.0$ & $14.8 \pm 2.9$ \\
PC $(\%)$ & $72.1 \pm 23$ & $92.6 \pm 4.7$ & $64.34 \pm 32.8$ & $65.6 \pm 18.9$ \\
INR & $1.3 \pm 0.27$ & $1.12 \pm 0.04$ & $1.74 \pm 0.89$ & $1.39 \pm 0.252$ \\
WBC $\left(10^{3} / \mu \mathrm{l}\right)$ & $7.22 \pm 4.9$ & $5.0 \pm 1.6$ & $6.84 \pm 3.19$ & $6.76 \pm 3.77$ \\
PLT $\left(10^{3} / \mu \mathrm{l}\right)$ & $134.6 \pm 41.6$ & $241 \pm 119$ & $167 \pm 52.6$ & $84.4 \pm 50.6$ \\
HGB $(\mathrm{g} / \mathrm{dl})$ & $9.9 \pm 3.9$ & $12.7 \pm 2.0$ & $12.6 \pm 1.66$ & $11.7 \pm 1.09$ \\
Creatinine $(\mathrm{mg} / \mathrm{dl})$ & $0.78 \pm 0.2$ & $0.9 \pm 0.11$ & $0.94 \pm 0.26$ & $1.12 \pm 0.34$ \\
\hline
\end{tabular}

Data expressed as mean \pm SD. 


\subsection{Peripheral Blood CD64 Expressions and Neutrophil CD64 Index in Patients and Control}

Both patients with HBV and HCV groups showed statistically significant higher values for neutrophil, lymphocyte and monocyte CD64 expressions than control group. The significant value for neutrophil CD64 expression in both patients groups was ( $\mathrm{P}$ value $=0.01$ and 0.01 respectively), lymphocyte CD64 expression $(\mathrm{P}$ value $=0.01$ and 0.00 respectively) and for monocyte CD64 expression ( $\mathrm{P}$ value $=0.00$ and 0.00 respectively), also neutrophil CD64 index showed statistically significant higher values in both patients groups than control group ( $\mathrm{P}$ value $=0.000$ and 0.000 respectively) Table 4 .

\subsection{Peripheral Blood CD64 Expressions and Neutrophil CD64 Index in Patients Presented with Different Stages of HBV Infection}

A statistically significant difference was detected between different stages of HBV infection as regard neutrophil, lymphocyte and monocyte CD64 expressions ( $\mathrm{P}$ value $=0.000$ between groups). Significantly higher values were detected

Table 3. Laboratory data for patients with HCV before and after treatment.

\begin{tabular}{|c|c|c|c|}
\hline \multirow{2}{*}{ Parameter } & \multicolumn{3}{|c|}{ Patients with chronic HCV } \\
\hline & Before treatment & After treatment & $P$ value \\
\hline Bilirubin (mg/dl) & $1.21 \pm 0.72$ & $1.01 \pm 1.17$ & 0.00 \\
\hline Albumin (g/dl) & $3.5 \pm 0.80$ & $3.62 \pm 0.66$ & NS \\
\hline $\operatorname{ALT}(\mathrm{U} / \mathrm{L})$ & $48.3 \pm 31.5$ & $33.7 \pm 39$ & 0.02 \\
\hline $\operatorname{AST}(\mathrm{U} / \mathrm{L})$ & $45.9 \pm 33$ & $34.8 \pm 27$ & 0.02 \\
\hline PT (seconds) & $13.6 \pm 1.15$ & $13.2 \pm 1.36$ & NS \\
\hline PC (\%) & $71.2 \pm 8.38$ & $77.2 \pm 8.6$ & 0.00 \\
\hline INR & $1.12 \pm 0.32$ & $1.09 \pm 0.47$ & 0.00 \\
\hline $\operatorname{WBC}\left(10^{3} / \mu \mathrm{l}\right)$ & $7.23 \pm 3.96$ & $7.08 \pm 4.32$ & NS \\
\hline $\operatorname{PLT}\left(10^{3} / \mu \mathrm{l}\right)$ & $180.2 \pm 38.7$ & $190 \pm 56.4$ & NS \\
\hline HGB (g/dl) & $10.4 \pm 2.46$ & $12.2 \pm 1.18$ & 0.00 \\
\hline Creatinine (mg/dl) & $1.04 \pm 0.28$ & $1.03 \pm 0.59$ & NS \\
\hline
\end{tabular}

Data expressed as mean \pm SD, paired student- $t$-test was used.

Table 4. Mean values of peripheral blood CD64 expressions and neutrophil CD index in patients and control.

\begin{tabular}{cccccc}
\hline \multirow{2}{*}{ Parameter } & \multicolumn{3}{c}{ Patients and control } \\
\cline { 2 - 6 } & control & HBV & P value & HCV & P value \\
\hline Neutophil CD expression & $45.2 \pm 0.627$ & $47.6 \pm 2.32$ & 0.01 & $47.1 \pm 2.54$ & 0.01 \\
Lymphocyte CD expression & $5.90 \pm 0.286$ & $7.90 \pm 0.268$ & 0.01 & $9.17 \pm 0.382$ & 0.00 \\
Monocyte CD expression & $51.4 \pm 1.67$ & $85.4 \pm 4.57$ & 0.001 & $74.6 \pm 2.42$ & 0.00 \\
Neutrophil CD index & $0.536 \pm 0.448$ & $2.32 \pm 3.53$ & 0.000 & $0.82 \pm 0.43$ & 0.000 \\
\hline
\end{tabular}

P value $<0.05=$ significant, NS $=$ non-significant. Un-paired student- $t$-test was used . 
inpatients with acute infection than other stages. Their values were significantly increasing from patients with chronic hepatitis to LC to HCC. Also, there was statistically significant difference in neutrophil CD64 index between patients with different stages of HBV infection ( $\mathrm{P}$ value $=0.000$ between groups). $\mathrm{Pa}-$ tients with acute infection showed higher values than other stages, and its value was significantly increasing from patients with chronic hepatitis to LC to HCC. This is illustrated in Table 5 and Figures 2-5. Also significant higher values; for both expressions and neutrophil CD64 index, were detected in every stage of infection in comparison with control group $(\mathrm{P}$ value $=0.000)$.

\subsection{Peripheral Blood CD64 Expressions and Neutrophil CD64 Index in Patients with HCV Infection before and after Treatment}

The level of CD64 expressions for neutrophil, lymphocyte and monocyte decreased significantly after direct acting antiviral therapy $(\mathrm{P}$ value $=0.000)$, also neutrophil CD64 index decreased significantly after therapy $(\mathrm{P}$ value $=0.000)$,

Table 5. Mean values of peripheral blood CD64 expressions and neutrophil CD index in different stages of HBV infection.

\begin{tabular}{cccccc}
\hline \multirow{2}{*}{ Parameter } & \multicolumn{5}{c}{ Patients HBV } \\
\cline { 2 - 6 } & Acute & Chronic & Cirrhosis & HCC & P value \\
\hline Neutophil CD expression & $65.9 \pm 1.84$ & $49.74 \pm 1.95$ & $51.6 \pm 2.84$ & $57.8 \pm 1.92$ & 0.000 \\
Lymphocyte CD expression & $10.10 \pm 0.161$ & $8.62 \pm 0.32$ & $8.83 \pm 0.09$ & $8.98 \pm 0.308$ & 0.000 \\
Monocyte CD expression & $85.30 \pm 1.25$ & $53.1 \pm 2.79$ & $59.19 \pm 3.08$ & $62.2 \pm 1.07$ & 0.000 \\
Neutrophil CD index & $8.06 \pm 4.56$ & $0.726 \pm 0.57$ & $0.961 \pm 0.562$ & $1.04 \pm 0.645$ & 0.000 \\
\hline
\end{tabular}

$\mathrm{P}$ value $<0.05=$ significant. One Way ANOVA test was used between groups.

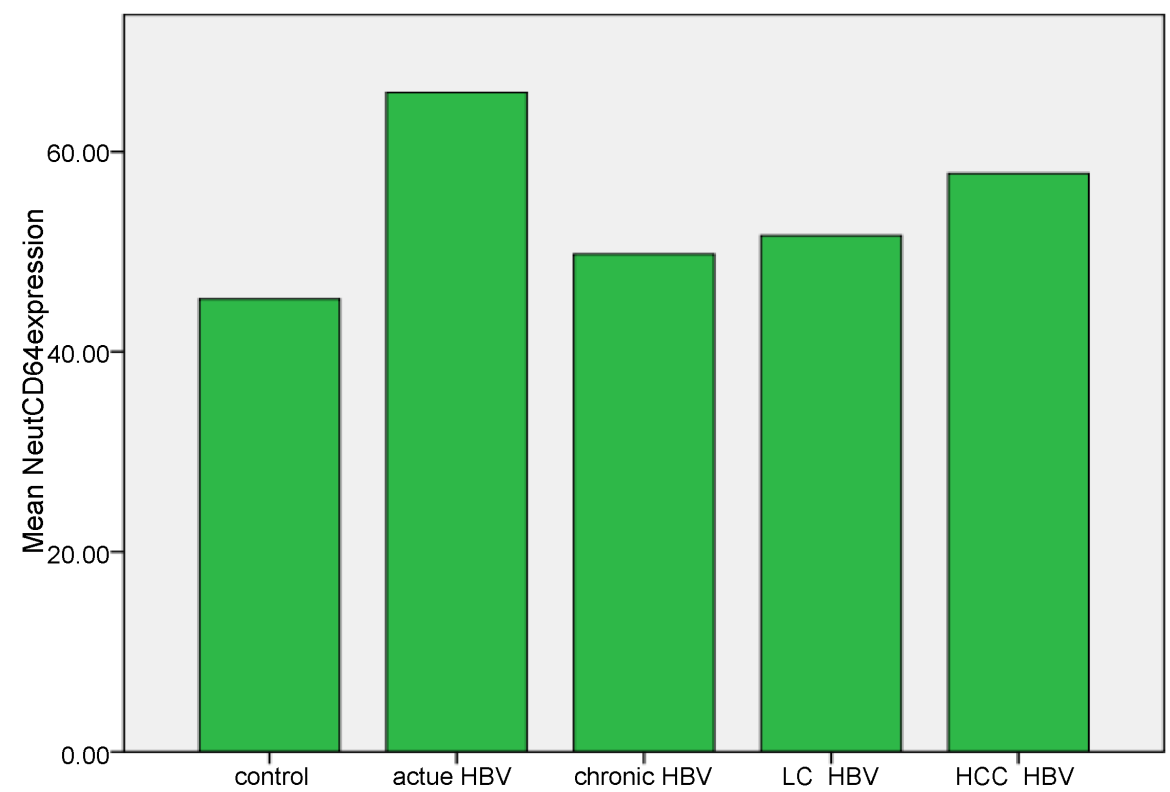

Figure 2. Mean neutrophil CD64 expression in stages of HBV infection and in control group. All stages of HBV was higher than control group. Patients with acute stage showed the highest values and progressive increase from chronic stage to LC to HCC. 


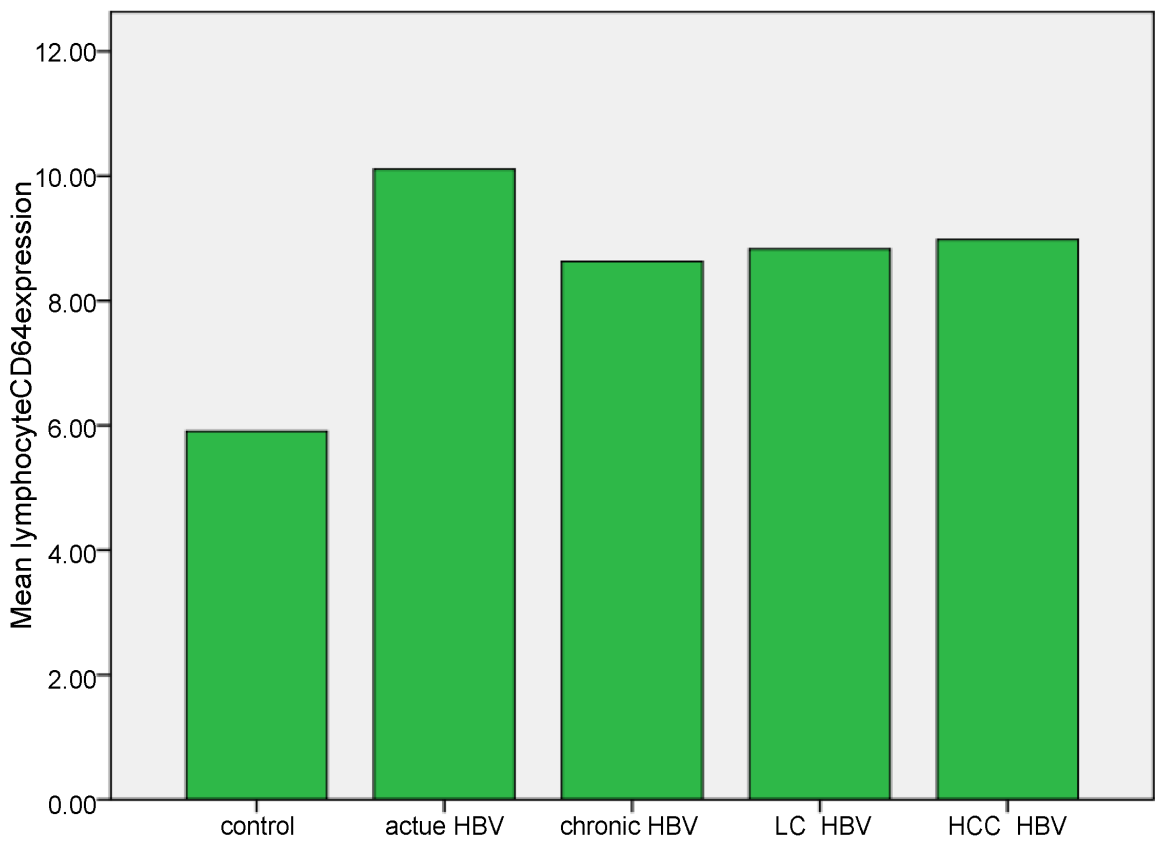

Figure 3. Mean lymphocyte CD64 expression in stages of HBV infection and in control group. All stages of HBV was higher than control group. Patients with acute stage showed the highest values and progressive increase from chronic stage to LC to HCC.

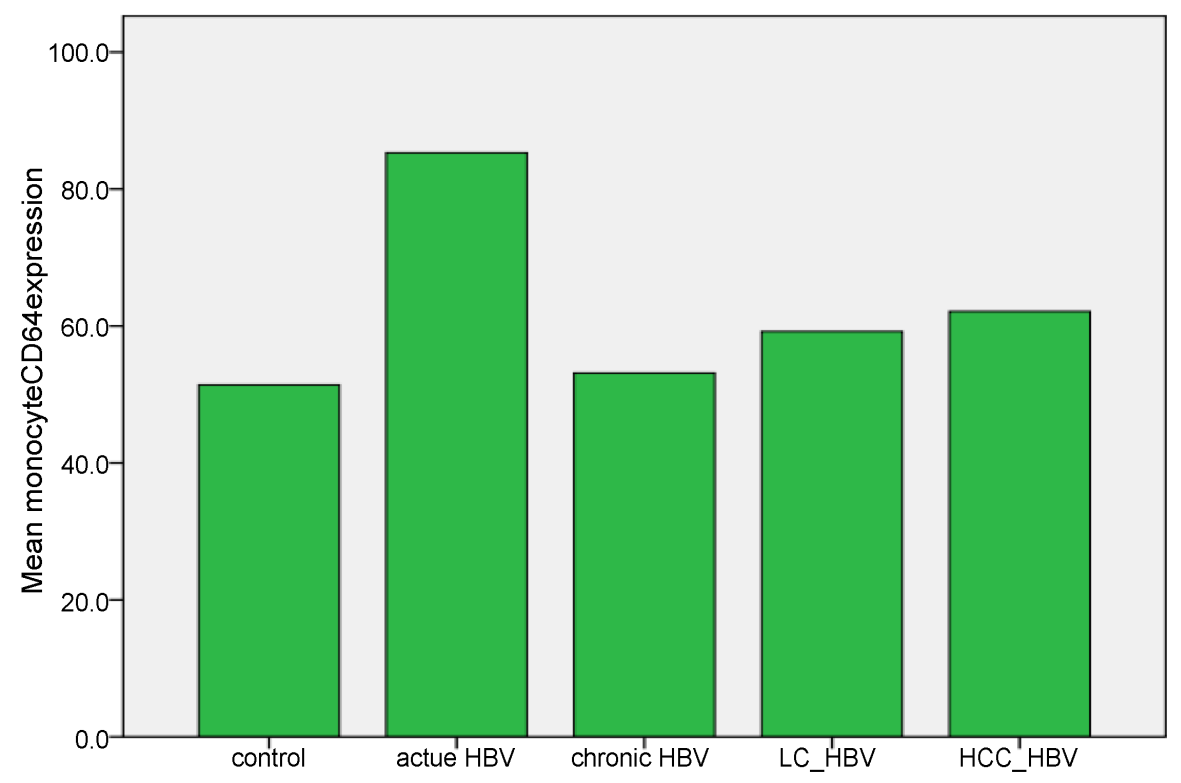

Figure 4. Mean monocyte CD64 expression in stages of HBV infection and in control group. All stages of HBV was higher than control group. Patients with acute stage showed the highest values and progressive increase from chronic stage to LC to HCC.

Table 6 and Figure 6.

\subsection{Correlations}

No significant correlation could be detected between, CD64 expressions and neutrophil CD64 index, and ALT, AST, PCR viraemia, Child-Pugh score in either group of patients. 


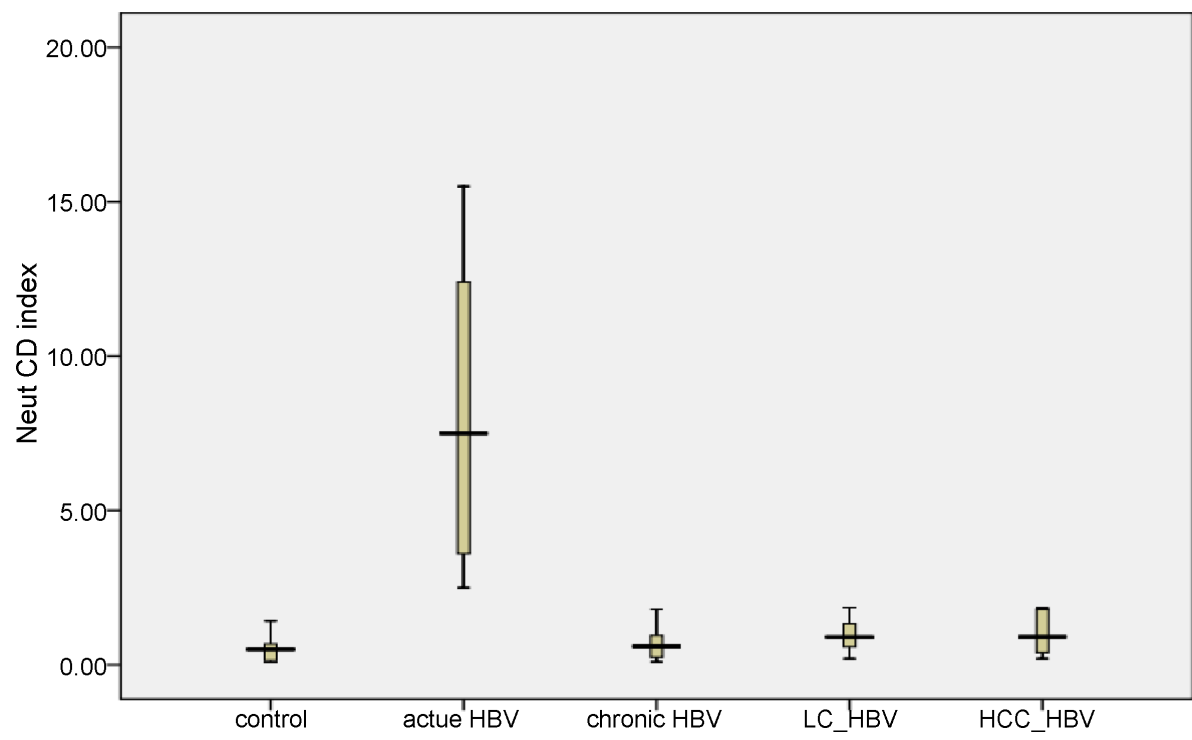

Figure 5. Mean value of neutrophil CD64 index in different stages of HBV infection and in control group. All stages of HBV were higher than control group. Patients with acute stage showed the highest values and progressive increase from chronic stage to LC to HCC.

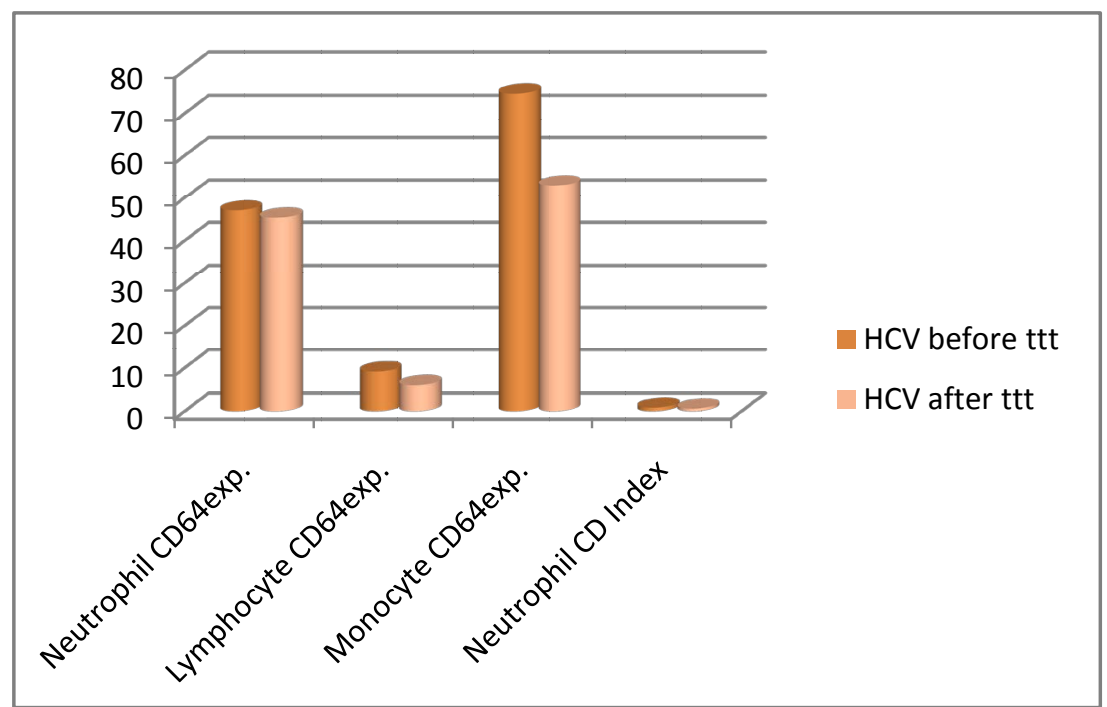

Figure 6. Mean values of neutrophil, lymphocyte and monocyte CD64 expression and neutrophil CD index in patients with HCV before and after direct acting antiviral therapy. Significant reduction in all values after treatment $(P$ value $=0.000)$.

Table 6. Peripheral blood CD 64 expressions and neutrophil CD index in patients with HCV before and after treatment.

\begin{tabular}{cccc}
\hline \multirow{2}{*}{ Parameter } & \multicolumn{3}{c}{ Patients with chronic HCV } \\
\cline { 2 - 4 } & Before treatment & After treatment & P value \\
\hline Neutophil CD expression & $47.1 \pm 2.54$ & $45.36 \pm 0.98$ & 0.000 \\
Lymphocyte CD expression & $9.17 \pm 0.382$ & $6.02 \pm 0.44$ & 0.000 \\
Monocyte CD expression & $74.6 \pm 2.42$ & $52.9 \pm 3.5$ & 0.000 \\
Neutrophil CD index & $0.82 \pm 0.43$ & $0.61 \pm 0.32$ & 0.000 \\
\hline
\end{tabular}

Data expressed as mean $\pm \mathrm{SD}$, paired student- $t$-test was used. 


\section{Discussion}

Infection with $\mathrm{HBV}$ induces both cellular and humoral immune response that cause liver cell damage either directly or through antibody-dependent cytotoxicity [17]. One of these antibodies is CD64, which is a receptor of IgG Fc fragment I of immunoglobulin $\mathrm{G}(\mathrm{IgG})$ that can be changed in HBV infected patients [10].

In recent years, several studies on Fcg receptor I (FcgRI) have confirmed that it could be a marker of infection. In resting neutrophils, CD64 is expressed at a very low level (approximately 1400 receptors per cell on average). However, the up-regulation of CD64 on the surface of neutrophils is induced by inflammatory cytokines such as interferon gamma [18] and granulocyte colony-stimulating factor [19].

In the current study we evaluated the possible significant role of peripheral blood CD64 expressions and neutrophil CD64 index in patients with different stages of $\mathrm{HBV}$ infection and in patients with chronic hepatitis $\mathrm{C}$ virus infection before and after treatment as a possible inflammatory markers for rapid and early detection of infection and as a prognostic, reliable and simple marker for detection of improvement or deterioration.

In this study, we found that the levels of neutrophil, lymphocyte and monocyte CD64 expressions were significantly higher in patients with acute hepatitis $B$ virus infection compared with healthy control group and with patients in different stages of chronic hepatitis B virus (chronic HBV infection without LC, chronic HBV related LC and chronic HBV related HCC), this may be related to severe inflammatory and immunological reaction in acute $\mathrm{HBV}$ infection. In other stages of chronic HBV infection, HCC patients showed the highest values than earlier stages including chronic infection and LC representing more progression of the disease and maximum intensity of the inflammatory and immunological reactions in those patients.

This was in agreement with the results of (Feng et al., 2015) whom recorded high level of peripheral blood neutrophil, monocyte and lymphocytes CD64 index at different stages of chronic hepatitis B virus infection and the level of CD64 index increase with increasing the duration of chronic HBV infection and reported that the level of lymphocyte CD64 index increased significantly than other indices [10].

Also, we found that neutrophil CD64 index was significantly higher in patients with acute HBV infection and in different stages of chronic HBV infection in comparison to control group indicating the continuity of inflammation in all these stages. Also, (Feng et al., 2015) reported significant increase in level of neutrophil CD64 index in all stages of chronic hepatitis B virus infection in comparison to control group [10].

Hepatitis $\mathrm{C}$ virus has been identified decades ago as a cause of chronic viral hepatitis that progress to cirrhosis and HCC. Only a small number of patients can clear the virus spontaneously during acute infection due to rapid induction of innate immune response, especially interferon (IFN) induced genes, and adaptive immune responses [20]. In contrary to other flaviviruses related to 
$\mathrm{HCV}$, and against hepatitis $\mathrm{B}$ virus (HBV), HCV causes chronic infection in most adults who are exposed to infection as the virus overcome innate and adaptive immune response, causing progression to fibrotic liver injury that finally lead to cirrhosis, liver failure and an increased risk of HCC [21].

The current study is the first study conducted to measure the dynamic changes of peripheral blood CD64 expressions and index in patients with chronic hepatitis $\mathrm{C}$ virus infection before and after treatment with DAA as a marker for detection of hepatic inflammation. In the current study, the level of peripheral blood CD64 expression for neutrophil, lymphocyte and monocyte and neutrophil CD64 index decreased significantly after treatment with direct acting antiviral therapy, which attributed to drug induced inhibition of inflammation and regulated immune response with subsequent down-regulation of CD64 index.

So the level of peripheral blood CD64 expression may be used as a marker to follow up the degree of hepatic inflammation in patients during treatment and early predict failure to response to treatment also can be used as a marker to detect progression of liver disease.

We can conclude that CD64 expressions and CD64 index were increased in HBV infected patients especially in the acute condition and changed with the course of the disease. And their levels significantly decreased after eradication of $\mathrm{HCV}$ infection with direct acting antiviral drugs, so their levels could be helpful for detecting the stage of liver damage and monitoring therapy.

The limitation of the current study was the relative small numbers of patients for each group, so further studies on large scales of population are needed for further evaluation.

\section{Conflict of Interest}

Authors declared that no conflict of interest and no financial support from any agency.

\section{References}

[1] World Health Organization (WHO) Hepatitis, C. (2011) Fact Sheet Number 164 http://www.who.int/mediacentre/factsheets/fs164/en/index.html

[2] Lavanchy, D. (2011) Evolving Epidemiology of Hepatitis C Virus. Clinical Microbiology and Infection, 17, 107-115. https://doi.org/10.1111/j.1469-0691.2010.03432.x

[3] van der Meer, A.J., Veldt, B.J., Feld, J.J., Wedemeyer, H., Dufour, J.F., Lammert, F., et al. (2012) Association between Sustained Virological Response and All-Cause Mortality among Patients with Chronic Hepatitis C and Advanced Hepatic Fibrosis. The Journal of the American Medical Association, 308, 2584-2593. https://doi.org/10.1001/jama.2012.144878

[4] Arase, Y., Kobayashi, M., Suzuki, F., Suzuki, Y., Kawamura, Y., Akuta, N., et al. (2013) Effect of Type 2 Diabetes on Risk for Malignancies Includes Hepatocellular Carcinoma in Chronic Hepatitis C. Hepatology, 57, 964-973. https://doi.org/10.1002/hep.26087

[5] Ott, J.J., Stevens, G.A., Groeger, J. and Wiersma, S.T. (2012) Global Epidemiology of Hepatitis B Virus Infection: New Estimates of Age-Specific HBsAg Seroprevalence 
and Endemicity. Vaccine, 30, 2212-2219.

https://doi.org/10.1016/j.vaccine.2011.12.116

[6] Goldstein, S.T., Zhou, F., Hadler, S.C., Bell, B.P., Mast, E.E. and Margolis, H.S. (2005) Amathematical Model to Estimate Global Hepatitis B Disease Burden and Vaccination Impact. International Journal of Epidemiology, 34, 1329-1339. https://doi.org/10.1093/ije/dyi206

[7] Papatheodoridis, G.V., Manolakopoulos, S., Liaw, Y.F. and Lok, A. (2012) Follow-Up Andindications for Liver Biopsy in HBeAg-Negative Chronic Hepatitis B Virus Infection with Persistently Normal ALT: A Systematic Review. Journal of Hepatology, 57, 196-202. https://doi.org/10.1016/j.jhep.2011.11.030

[8] Raimondo, G., Allain, J.P., Brunetto, M.R., Buendia, M.A., Chen, D.S., Colombo, M., et al. (2008) Statements from the Taormina Expert Meeting on Occult Hepatitis B Virus Infection. Journal of Hepatology, 49, 652-657.

https://doi.org/10.1016/j.jhep.2008.07.014

[9] Fattovich, G., Stroffolini, T., Zagni, I. and Donato, F. (2004) Hepatocellular Carcinoma Incirrhosis: Incidence and Risk Factors. Gastroenterology, 127, S35-S50. https://doi.org/10.1053/j.gastro.2004.09.014

[10] Feng, H., Yin, J., Han, Y.P., Zhou, X.Y. and Zhang, G.X. (2015) Lymphocyte CD64 Increased in Patients with Chronic HBV Infection. International Journal of Clinical and Experimental Medicine, 8, 10746-10752.

[11] Icardi, M., Erickson, Y., Kilborn, S., Stewart, B., Grief, B. and Scharnweber, G. (2009) CD64 Index Provides Simple and Predictive Testing for Detection and Monitoring of Sepsis and Bacterial Infection in Hospital Patients. Journal of Clinical Microbiology, 47, 3914-3919. https://doi.org/10.1128/JCM.00628-09

[12] Wang, X., Li, Z.Y., Zeng, L., Zhang, A.Q., Pan, W., Gu, W. and Jiang, J.X. (2015) Neutrophil CD64 Expression as a Diagnostic Marker for Sepsis in Adult Patients: Ameta-Analysis. Critical Care, 19, 245. https://doi.org/10.1186/s13054-015-0972-z

[13] Corrales-Aguilar, E., Trilling, M., Hunold, K., Fiedler, M., Le, V.T.K., et al. (2014) Human Cytomegalovirus Fcc Binding Proteins gp34 and gp68 Antagonize Fcc Receptors I, II and III. PLOS Pathogens, 10.

[14] Mokuda, S., Miyazaki, T., Saeki, Y., Masumoto, J., Kanno, M. and Takasugi, K. (2015) Epstein-Barr Virus-Related MTX-LPD in Rheumatoid Arthritis Patients Exhibits a Viral Pattern of the CD64 and CD35 Expression on Neutrophils: Three Case Reports. Modern Rheumatology, 25, 166-168. https://doi.org/10.3109/14397595.2013.875641

[15] Mokuda, S., Doi, O. and Takasugi, K. (2012) Simultaneous Quantitative Analysis of the Expression of CD64 and CD35 on Neutrophils as Markers to Differentiate between Bacterial and Viral Infections in Patients with Rheumatoid Arthritis. Modern Rheumatology, 22, 750-757. https://doi.org/10.3109/s10165-011-0587-4

[16] European Association for the Study of the Liver. EASL Recommendations on Treatment of Hepatitis C 2015. (2015) Journal of Hepatology, 63, 199-236. https://doi.org/10.1016/j.jhep.2015.03.025

[17] Nuutila, J. (2010) The Novel Applications of the Quantitative Analysis of Neutrophil Cell Surface FcgammaRI (CD64) to the Diagnosis of Infectious and Inflammatory Diseases. Current Opinion in Infectious Diseases, 23, 268-274. https://doi.org/10.1097/QCO.0b013e32833939b0

[18] Quayle, J.A., Watson, F., Bucknall, R.C. and Edwards, S.W. (1997) Neutrophils from the Synovial Fluid of Patients with Rheumatoid Arthritis Express the High Affinity Immuno-Globulin G Receptor, Fc Gamma RI (CD64): Role of Immune Complexes and Cytokines in Induction of Receptor Expression. Immunology, 91, 266-273. 
https://doi.org/10.1046/j.1365-2567.1997.00249.x

[19] Gericke, G.H., Ericson, S.G., Pan, L., Mills, L.E., Guyre, P.M. and Ely, P. (1995) Mature Polymorpho-Nuclear Leukocytes Express High-Affinity Receptors for IgG (Fc Gamma RI) After Stimulation with Granulocyte Colony-Stimulating Factor (G-CSF). Journal of Leukocyte Biology, 57, 455-461.

[20] Markus, H. and Heim, R.T. (2014) Innate and Adaptive Immune Responses in HCV Infections. Journal of Hepatology, 61, S14-S25. https://doi.org/10.1016/j.jhep.2014.06.035

[21] Freeman, A.J., Marinos, G., Ffrench, R.A. and Lloyd, A.R. (2001) Immuno-Pathogenesis of Hepatitis C Virus Infection. Immunology and Cell Biology, 79, 515 536. https://doi.org/10.1046/j.1440-1711.2001.01036.x

Submit or recommend next manuscript to SCIRP and we will provide best service for you:

Accepting pre-submission inquiries through Email, Facebook, LinkedIn, Twitter, etc. A wide selection of journals (inclusive of 9 subjects, more than 200 journals) Providing 24-hour high-quality service User-friendly online submission system Fair and swift peer-review system Efficient typesetting and proofreading procedure Display of the result of downloads and visits, as well as the number of cited articles Maximum dissemination of your research work

Submit your manuscript at: http://papersubmission.scirp.org/

Or contact ojgas@scirp.org 